\title{
Glycothermal Synthesis and Characterization of 3Y-TZP Nanoparticles
}

\author{
Jeong-Hwan Song ${ }^{\dagger}$ and Ju-Hee Lee* \\ Department of Information \& Electronic Materials Engineering, PaiChai University, Daejeon 302-735, KOREA \\ *Department of Dental Laboratory Technology, Daejeon Health Sciences College, Daejeon 300-711, KOREA
}

(Received June 30, 2009 : Received in revised form July 22, 2009 : Accepted August 3, 2009)

\begin{abstract}
In this study, 3 mol\% yttria-tetragonal zirconia polycrystal (3Y-TZP) nanoparticles were synthesized by the glycothermal method under various reaction temperatures and times. The co-precipitated precursor of 3Y-TZP was prepared by adding $\mathrm{NH}_{4} \mathrm{OH}$ to starting solutions, and then the mixtures were placed in an autoclave reactor. Tetragonal yttria-doped zirconia nanoparticles were afforded through a glycothermal reaction at a temperature as low as $220^{\circ} \mathrm{C}$, using co-precipitated gels of $\mathrm{ZrCl}_{4}$ and $\mathrm{YCl}_{3} \cdot 6 \mathrm{H}_{2} \mathrm{O}$ as precursors and 1,4butanediol as the solvent. The synthesized 3Y-TZP particles were characterized by X-ray diffraction (XRD), field emission scanning electron microscopy (FESEM), transmission electron microscopy (TEM), and Raman spectroscopy. The 3Y-TZP particles have a stable tetragonal phase only at glycothermal temperatures above $200{ }^{\circ} \mathrm{C}$. To investigate phase transition, the 3Y-TZP particles were heat treated from 400 to $1400{ }^{\circ} \mathrm{C}$ for $2 \mathrm{~h}$. Raman analysis indicated that, after heat treatment, the tetragonal phase of the 3Y-TZP particles remained stable. The results of this study, therefore, suggest that 3Y-TZP powders can be prepared by the glycothermal method.
\end{abstract}

Key words 3Y-TZP, nanoparticle, glycothermal, 1,4-butanediol, Raman.

\section{Introduction}

Zirconia ceramics show considerable potential for use in structural and functional applications due to their excellent mechanical, electrical, thermal, and optical properties. ${ }^{1)}$ Yttria-stabilized tetragonal zirconia polycrystal (Y-TZP) has attracted much attention as a promising structural material due to its excellent fracture toughness and high strength in applications such as cutting tools, valve guides, extrusion dies, grinding media, etc. ${ }^{2,3)}$ Yttria-stabilized cubic zirconia (Y-CSZ) can be considered a candidate for a solid-electrolyte material in ceramic fuel cells because of its excellent oxygen-ion conductivity. ${ }^{4,5}$ Furthermore, zirconia-based materials have become increasingly important in all-ceramic dental restorations due to their favorable esthetics and their outstanding biological compatibility and transparency.

Pure zirconia has three polymorphisms at atmospheric pressure : monoclinic (from room temperature up to $1170^{\circ} \mathrm{C}$ ), tetragonal $\left(1170-2370{ }^{\circ} \mathrm{C}\right)$, and cubic $\left(2370^{\circ} \mathrm{C} \text { and above) }\right)^{2,6)}$ The tetragonal to monoclinic phase transformation is associated with a volume expansion of approximately $3-4 \%$, with cracks arising from the sintering temperature during

Corresponding author

E-Mail : song_jeonghwan@pcu.ac.kr (J. -H. Song) cooling. To inhibit these phase transformations, several aliovalent oxides such as $\mathrm{CaO}, \mathrm{MgO}, \mathrm{CeO}_{2}$, or $\mathrm{Y}_{2} \mathrm{O}_{3}$ are added; these oxides allow the stabilization of the cubic or tetragonal phases at room temperature. ${ }^{7,8)}$ TZP materials are extensively used for dental restorations in the biomedical field because of their excellent mechanical properties, especially when $3 \mathrm{~mol} \%$ yttria is used as the stabilizer dopant.

The synthesis of nanocrystalline particles has been considered extremely important in the improvement of the mechanical and chemical properties of zirconia-based materials.9) Various wet chemical methods, such as sol-gel synthesis, ${ }^{10)}$ polymeric precursor route, ${ }^{11)}$ combustion synthesis, ${ }^{12)}$ hydrothermal treatment, ${ }^{13)}$ and co-precipitation from metal aqueous solutions ${ }^{14)}$ have been explored for the preparation of diverse doped zirconia powders due to the impressive chemical/physical homogeneity and good sinterability of the products. Only a few studies have investigated the use of glycol media and the glycothermal method to synthesize crystalline ceramic powders. Previous studies have shown that metal oxide powders can potentially be prepared by glycothermal synthesis in 1,4-butanediol solutions. ${ }^{15,16)}$ Crystalline ceramic powders can directly be prepared by glycothermal synthesis at reaction temperatures and pressures lower than those required by the 
hydrothermal method. The glycothermal process does not require heat treatment for crystallization and mineralizers for the formation of anhydrous crystalline materials in some cases because 1,4-butanediol can act as an oxidizer. Therefore, this process dose not involves contamination by alkalis such as $\mathrm{KOH}$ and $\mathrm{NaOH}$, which are commonly used in the conventional hydrothermal method.

In this work, 3Y-TZP nanoparticles were prepared by the glycothermal method. The characteristics of the particles obtained by glycothermal reaction were evaluated by X-ray diffraction (XRD), scanning electron microscopy (SEM), and transmission electron microscopy (TEM). The structural evolutions of the 3 Y-TZP nanoparticles after cooling from heat treatment temperature were examined by Raman spectroscopy.

\section{Experimental procedure}

The process for the preparation of $3 \mathrm{~mol} \%$ yttria-doped zirconia by glycothermal treatment in a 1,4-butanediol (98.0\%, Oriental Chem.) solution is schematically illustrated in Fig. 1. Stoichiometric amounts of $\mathrm{ZrCl}_{4}$ (99.5\%, Aldrich Chemical Co.) and $\mathrm{YCl}_{3} \cdot 6 \mathrm{H}_{2} \mathrm{O}(99.9 \%$, Aldrich Chemical Co.) were dissolved in $25 \mathrm{ml}$ of $\mathrm{CO}_{2}$-free deionized water (ice cold water) to afford an aqueous solution of $1 \mathrm{M}$ $\mathrm{ZrCl}_{4}$ containing a source of $\mathrm{Y}$. The ice cold water was used because the metal chloride can be readily hydrolyzed by reacting with the water in the air and evolves a $\mathrm{Cl}_{2}$ gas because of its large vapor pressure at room temper-

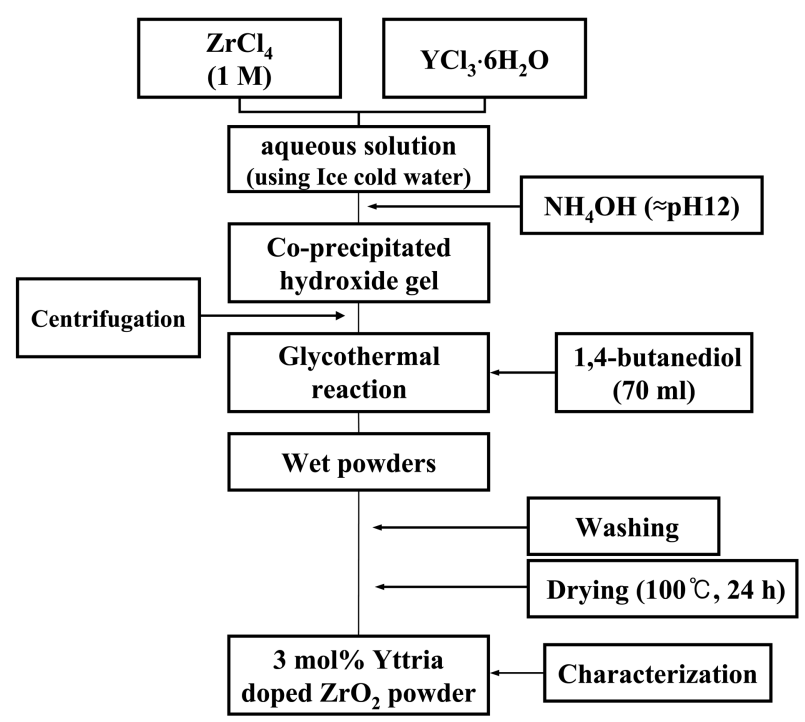

Fig. 1. Experimental flowchart for the synthesis of $3 \mathrm{Y}-\mathrm{TZP}$ powders using the glycothermal method. ature. This aqueous solution was maintained in a stable state without precipitation at room temperature. Co-precipitated precursors of 3Y-TZP were immediately prepared by drop-wise addition of $\mathrm{NH}_{4} \mathrm{OH}$ with $\mathrm{pH} \approx 12$ (28\%, DC Chem.) into $25 \mathrm{ml}$ of the starting aqueous solutions with vigorous stirring. The co-precipitated precursor was separated and washed with $\mathrm{CO}_{2}$-free deionized water in three cycles for 10 -min centrifugation at $10,000 \mathrm{rpm}$, until no residual $\mathrm{Cl}^{-}$remained.

The obtaining precursor and $70 \mathrm{ml}$ of 1,4-butanediol solvent were combined in a $100 \mathrm{ml}$ Teflon container, which was then placed in the stainless-steel pressure vessel of the autoclave reactor. The reaction autoclave was then heated to the desired temperature at a rate of $2{ }^{\circ} \mathrm{C} / \mathrm{min}$. The reaction time at each desired temperature was 6 to $24 \mathrm{~h}$. After glycothermal reaction, the autoclave reactor was cooled to $\sim 40{ }^{\circ} \mathrm{C}$. The particles were separated and washed with $\mathrm{CO}_{2}$-free deionized water and ethanol. After washing, the obtained particles were dried in a $100{ }^{\circ} \mathrm{C}$ oven for $24 \mathrm{~h}$.

The dried particles were analyzed for phase composition and crystal structure using X-ray diffraction (XRD, $\mathrm{Cu}$ $\mathrm{K} \alpha_{1}, 30 \mathrm{kV}-30 \mathrm{~mA}$, Shimazu, Japan) over the $2 \theta$ range from $20^{\circ}$ to $80^{\circ}$ at a scan rate of $2^{\circ} / \mathrm{min}$. The morphology of the synthesized particles was observed using fieldemission scanning microscopy (FESEM, Hitachi S4800, Japan) and transmission electron microscopy (TEM, Jeol JEM-2100F, Japan). For each specimen, Raman spectroscopy measurements of the obtained 3Y-TZP particles were performed over the range of $100-1000 \mathrm{~cm}^{-1}$ using an FT Raman spectrometer (Raman, Bruker RFS 100/S, Germany) using an excitation wavelength of $1064 \mathrm{~nm}$ from a 100-mW $\mathrm{Nd}$ : YAG laser. The main reason for using Raman spectroscopy is that the tetragonal and monoclinic polymorphs of zirconia are reported to have distinct and characteristic Raman spectra.

\section{Results and discussion}

Fig. 2 presents the XRD results of the obtained powders at various glycothermal conditions for the synthesis of pure 3Y-TZP. The XRD patterns show that the synthesized zirconia powders had a single phase. The precursor derived from co-precipitation is amorphous, as shown in Fig. 2(a). The powders obtained below $180{ }^{\circ} \mathrm{C}$ for $24 \mathrm{~h}$ still show an amorphous state (Figs. 2(b and c)). The crystallization of $3 \mathrm{~mol} \%$ yttira-doped zirconia powders prepared directly at a reaction temperature of $>200{ }^{\circ} \mathrm{C}$ for $24 \mathrm{~h}$ occurred 


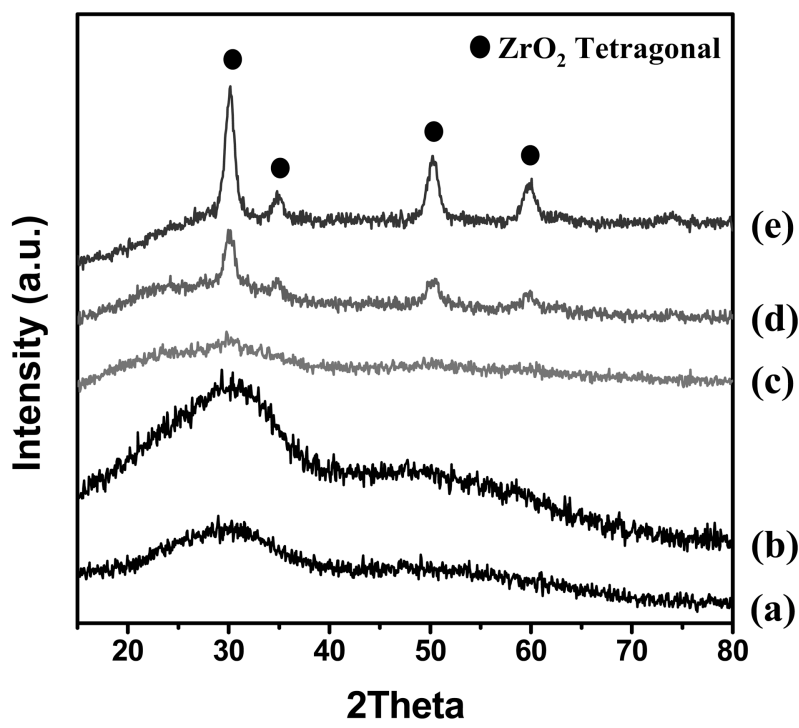

Fig. 2. XRD patterns of 3 Y-TZP powder obtained by the glycothermal method at various reaction temperatures for $24 \mathrm{~h}$. (a) co-precipitated precursor, (b) at $160{ }^{\circ} \mathrm{C}$, (c) at $180{ }^{\circ} \mathrm{C}$, (d) at $200{ }^{\circ} \mathrm{C}$, and (e) at $220{ }^{\circ} \mathrm{C}$.

without the formation of intermediate phases (Figs. 2(d and e)). Only the crystalline phase was observed corresponding to the tetragonal structure of zirconia (JCPDS card 881007). With an increase in the reaction temperature, the intensity of the diffraction peak increases. The powders prepared in short glycothermal reaction times of less than $12 \mathrm{~h}$ are amorphous, whereas the powders synthesized at reaction times of $>12 \mathrm{~h}$ could be crystalline. The lattice parameters of the obtained powder were determined to be $a=0.361 \mathrm{~nm}$ and $c=0.517 \mathrm{~nm}$, using the least square refinement method. This value agreed well with the lattice constant of the tetragonal structure of 3Y-TZP reported in a previous study $\left(a_{\mathrm{t}}=0.511 \mathrm{~nm}\right.$ and $\left.c_{\mathrm{t}}=0.518 \mathrm{~nm}\right) .{ }^{17}$

The average crystallite sizes were determined from XRD patterns according to Scherrer's equation:

$$
D=\frac{k \lambda}{\beta \cos \theta}
$$

where $D$ is the average crystallite size, $k$ is a constant equal to $0.94, \theta$ is the angle (101) of the main peak, $\lambda$ is the X-ray wavelength equal to $1.5406 \AA$, and $\beta$ is the full width at the half peak maximum. The average crystallite size of the $3 \mathrm{Y}$-TZP powders obtained at $220^{\circ} \mathrm{C}$ for $24 \mathrm{~h}$ was approximately $10.0 \mathrm{~nm}$, as shown in Fig. 2(e).

Fig. 3 shows a photomicrograph of the 3 Y-TZP powders taken by FESEM. Although the obtained powder was agglomerated to some extent, it was observed that the particles had a uniform distribution with a size of 20-30 nm

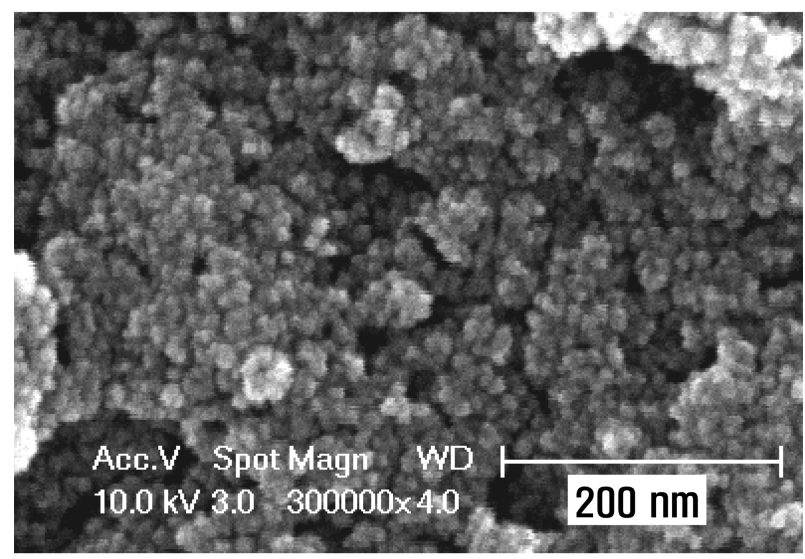

Fig. 3. FESEM photomicrograph of the $3 \mathrm{Y}$-TZP powder obtained by glycothermal reaction at $220^{\circ} \mathrm{C}$ for $24 \mathrm{~h}$.

and a spherical polygonal shape. The size of the 3Y-TZP particles prepared by glycothermal synthesis decreased with an increase in the reaction temperature because higher reaction temperatures generally promoted the dehydration reaction on the surface of the co-precipitated precursor. ${ }^{18)}$

TEM was performed to investigate the primary particle size and morphology. As shown in the TEM images of Fig. $4(\mathrm{a})$, it is clear that the spherical polygonal morphology of the $3 \mathrm{Y}-\mathrm{TZP}$ particles prepared by glycothermal reaction at $220{ }^{\circ} \mathrm{C}$ for $24 \mathrm{~h}$ are well-dispersed; the crystals have a relatively uniform distribution. The primary particles observed by TEM showed an approximate size of 10-15 nm with the average crystallite size value estimated from XRD. The high resolution transmission electron microscopy (HRTEM) image of the inset in Fig. 4(a) shows an enlargement of the area indicated. A tetragonal atomic arrangement is regularly observed with the incident electron beam aligned along the [010] zone axis of 3Y-TZP. The crystallographic array shows an interplanar distance of $0.294 \mathrm{~nm}$ as (101) planes of 3Y-TZP.

Fig. 4(b) is a schematic illustration representing the tetragonal structure and atom configuration of 3Y-TZP. The $d$ value $(d=0.296 \mathrm{~nm})$ calculated using the lattice constant of the tetragonal structure is very similar to that estimated by analysis of the HRTEM image.

Raman analysis investigated the effect of temperature dependence on the heat treatment of the 3Y-TZP powders prepared at $220^{\circ} \mathrm{C}$ for $24 \mathrm{~h}$, as shown Fig. 5. Monoclinic $\mathrm{ZrO}_{2}$ has a characteristic spectrum with 18 theoretically determined Raman active modes, while tetragonal zirconia has only 6 typical bands of the different Raman modes because of its higher symmetry. The band at $147 \mathrm{~cm}^{-1}$ is assigned to $\left(\mathrm{O}_{\mathrm{I}}-\mathrm{Zr}-\mathrm{O}_{\mathrm{I}}\right)$ and $\left(\mathrm{Zr}-\mathrm{O}_{\mathrm{I}}-\mathrm{Zr}\right)$ bending; that at $259 \mathrm{~cm}^{-1}$ 
(a)

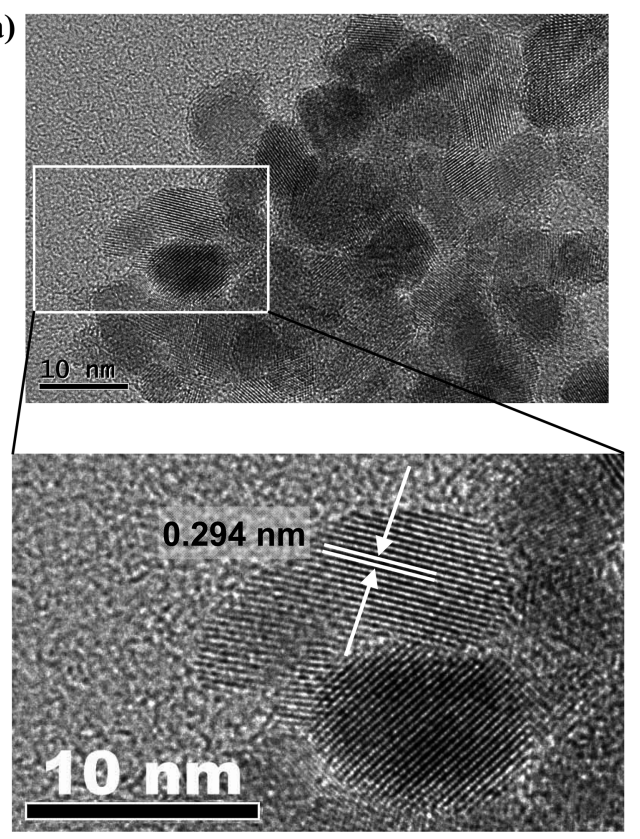

(b)
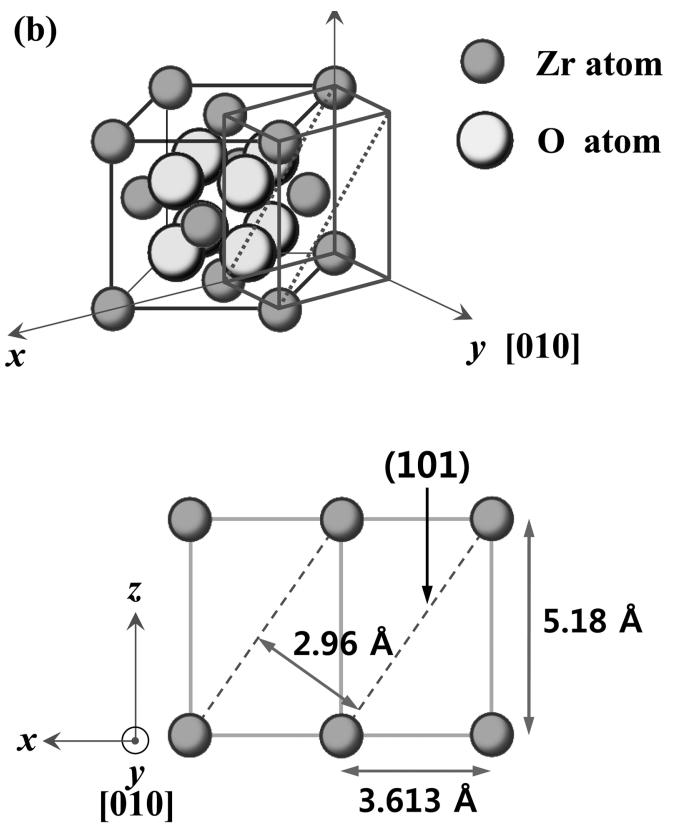

Fig. 4. (a) TEM and HRTEM images of the $3 \mathrm{Y}-\mathrm{TZP}$ powder obtained by glycothermal reaction at $220^{\circ} \mathrm{C}$ for $24 \mathrm{~h}$, (b) A schematic illustration of the tetragonal structure and atom configuration.

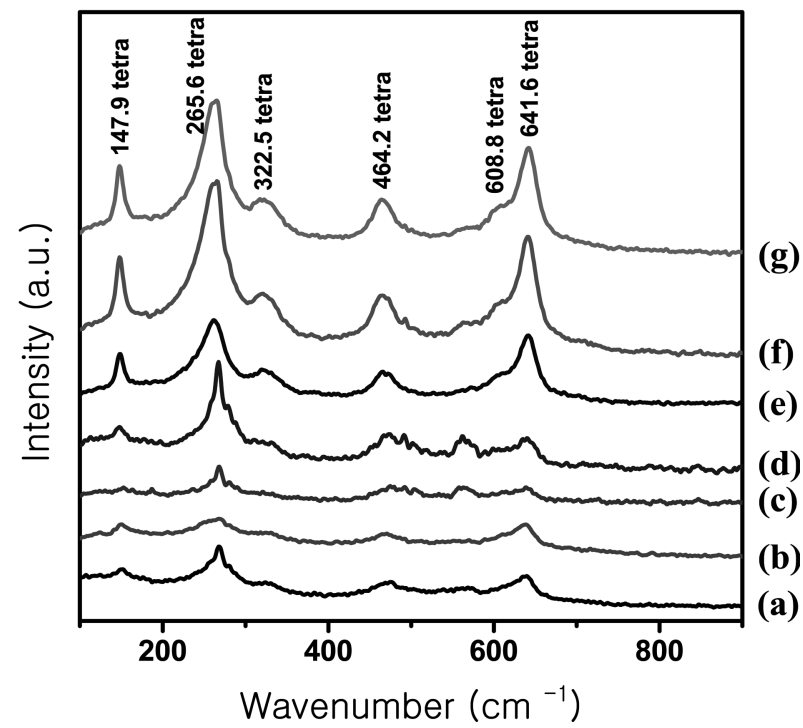

Fig. 5. Raman spectra with various heat treatment temperatures of the 3Y-TZP powder obtained at $220^{\circ} \mathrm{C}$ for $24 \mathrm{~h}$. (a) asprepared powder, (b) $400{ }^{\circ} \mathrm{C}$, (c) $600{ }^{\circ} \mathrm{C}$, (d) $800{ }^{\circ} \mathrm{C}$, (e) $1000{ }^{\circ} \mathrm{C}$, (f) $1200{ }^{\circ} \mathrm{C}$, and (g) $1400{ }^{\circ} \mathrm{C}$.

to $\left(\mathrm{Zr}-\mathrm{O}_{\mathrm{II}}\right)$ bending; and those at 464 and $322 \mathrm{~cm}^{-1}$ to $\mathrm{Zr}$ $\mathrm{O}_{\mathrm{I}} / \mathrm{O}_{\text {II }}$ stretching and to the coupling $\mathrm{O}_{\mathrm{I}}\left(\right.$ or $\left.\mathrm{O}_{\text {II }}\right)-\mathrm{Zr}-\mathrm{O}_{\mathrm{I}}$ (or $\mathrm{O}_{\mathrm{II}}$ ). The bands at 606 and $642 \mathrm{~cm}^{-1}$ are also assigned to (Zr$\left.\mathrm{O}_{\mathrm{I}}\right)$ stretching. ${ }^{19)}$ In all of the samples, after cooling from each heat treatment temperature, six Raman lines, occurring at $147.9,265.6,322.5,464.2,608.8$, and $641.6 \mathrm{~cm}^{-1}$ could be observed. None of the Raman doublet lines occurring at 180 and $190 \mathrm{~cm}^{-1}$ of the monoclinic phase were observed in Fig. 5; they were identified with the typical characteristics of the tetragonal phase. These results suggest that the primary crystal phase of the $3 \mathrm{~mol} \%$ yttria-doped zirconia nanoparticles was the tetragonal phase. The intensity of the Raman spectra increases with the heat treatment temperature because higher temperatures promote crystallinity in the tetragonal phase.

\section{Conclusion}

Nano-sized 3Y-TZP particles have been synthesized by the glycothermal reaction of co-precipitated precursors from stoichiometric amounts of $\mathrm{ZrCl}_{4}$ and $\mathrm{YCl}_{3} \cdot 6 \mathrm{H}_{2} \mathrm{O}$ under autogenous vapor pressures, with the use of 1,4butanediol glycol as the solvent. From TEM and XRD analysis, this work shows that nanoparticles were directly obtained in the $\mathrm{Y}_{2} \mathrm{O}_{3}$-doped $\mathrm{ZrO}_{2}$ with a stable tetragonal phase at $200{ }^{\circ} \mathrm{C}$ for $24 \mathrm{~h}$ without morphological change. The average crystallite size of the synthesized 3 Y-TZP nanoparticles was approximately $10 \mathrm{~nm}$ with a relatively uniform distribution. Furthermore, it was demonstrated that the stabilization of 3Y-TZP particles can be investigated by varying the temperature conditions of the heat treatment from 400 to $1400{ }^{\circ} \mathrm{C}$. The effect of temperature dependence was investigated by Raman analysis. The prepared 3Y-TZP powders were able to maintain a stable tetragonal phase regardless of the heat treatment temperature conditions. 


\section{References}

1. E.C. Subbara, Science and Technology of Zirconia, Adv. in Ceramics vol.3, p.1-24, eds., A. H. Heuer, L. W. Hobbs (The American Ceramic Society, Columbus, Ohio, 1981).

2. R. C. Garvie, R. H. Hannink and R. T. Pascoe, Nature, 258, 703 (1975).

3. R. C. Garvie, J. Phys. Chem., 82, 218 (1978).

4. P. Holtappels and C. Bagger, J. Eur. Ceram. Soc., 22(1), 41 (2002).

5. I. Zhitomirsky and A. Petric, J. Eur. Ceram. Soc., 20(12), 2055 (2000)

6. J. Cai, C. Raptis, Y. S. Raptis and E. Anastassaki, Phys. Rev. B, 51, 201 (1995).

7. C. Piconi and G. Maccauro, Biomaterials, 20, 1 (1999).

8. D. J. Green, R. H. Hannink and M. V. Swain, Transformation toughening of ceramics. Boca Raton, Fl: CRC (1989).

9. T. G. Nieh and J. Wadsworth, Acta Mater., 38, 1121 (1990).

10. J. Livage, F. Beteille, C. Rouse, M. Chatry and P.
Davidson, Acta Mater., 46, 743 (1998).

11. A. L. Quinelato, E. Longo, L. A. Perazolli and J. A. Varela, J. Eur. Ceram. Soc., 20, 1077 (2000).

12. R. E. Juarez, D. G. Lamas, G. E. Lascalea and N. E. Walsöe de Reca, J. Eur. Ceram. Soc., 20, 133 (2000).

13. G. Dell'Agli and G. Mascolo, J. Eur. Ceram. Soc., 20, 139 (2000).

14. D. Segal, Key Eng. Mater., 153, 241 (1998).

15. M. Inoue, H. Tanino, Y. Kondo and T. Inui, J. Am. Ceram. Soc., 72 (2), 352 (1989).

16. M. Inoue, J. Phys.: Condens. Matter, 16, S1291-S1303 (2004).

17. C. Chang and S. Jon, CIMTEC 2002 Proc., 4, 761 (2002).

18. Y. J. Jung, D. Y. Lim, J. S. Nho, S. B. Cho, R. E. Riman and B. W. Lee, J. Crystal Growth, 274, 638 (2005).

19. Y. Gogotsi and V. Domnich, in High-Pressure Surface Science and Engineering (Materials Science and Engineering), (CRC Press, Taylor \& Francis, 2003) p. 467-520. 